\title{
Antifibrotic therapies reduce mortality and hospitalization among Medicare beneficiaries with idiopathic pulmonary fibrosis
}

\author{
Joshua Mooney, MD; Sheila R Reddy, PhD, MSc, RPh; Eunice Chang, PhD; Michael S Broder, MD, MSHS; \\ Sohum Gokhale, MPH; and Mitra Corral, MS, MPH
}

\section{What is already known about this subject}

- Idiopathic pulmonary fibrosis (IPF) is a chronic, progressive fibrotic interstitial lung disease of unknown cause that is characterized by the absence of an identifiable cause and a specific radiologic or pathologic pattern of usual interstitial pneumonia.

- Despite the acceptance of antifibrotic drug therapy into IPF treatment guidelines, research has shown that many patients remain untreated.

\begin{abstract}
What this study adds
- This study revealed evidence of the effectiveness of antifibrotic treatment on reducing hospitalization and death among older patients with advanced age (ie, $>80$ years), which is a population that has been excluded from key clinical trials despite being disproportionately affected by IPF.

- This study lends support to previous research that has suggested a strong correlation between respiratory hospitalization and death; it differentiates itself from previous research by focusing on an older population with fee-for-service Medicare coverage, while also using propensity score matching methods to compare treated vs untreated patients with IPF.
\end{abstract}

IPF diagnosis) during the study period (January 1, 2010-December 31, 2017). Patients who initiated antifibrotic treatment (pirfenidone or nintedanib) between October 15, 2014 (FDA approval date) and December 31, 2017 (ie, treated patients) were compared with those who did not receive treatment during a historical period (January 1,2012 -October 14,2014 ) before the availability of antifibrotics (ie, untreated historical controls). Patients were matched by propensity score, and the outcomes, mortality, and hospitalization (all cause and respiratory related) were compared using a Cox proportional hazards model.

RESULTS: We identified 4,641 treated patients and 4,641 propensity score-matched

\author{
Author affiliations \\ Joshua Mooney, MD, Department of \\ Medicine, Stanford University, Stanford, \\ CA. Sheila R Reddy, PhD, MSc, RPh; Eunice \\ Chang, PhD; Michael S Broder, MD, MSHS; \\ and Sohum Gokhale, MPH, Partnership for \\ Health Analytics, LLC, Beverly Hills, CA. \\ Mitra Corral, MS, MPH, Genentech, Inc., \\ South San Francisco, CA. \\ AUTHOR CORRESPONDENCE: \\ Mitra Corral, corral.mitra@gene.com \\ J Manag Care Spec Pharm. \\ 2021;27(12):1724-33 \\ Copyright $\odot 2021$, Academy of Managed \\ Care Pharmacy. All rights reserved.
}

controls who met all study criteria; 352 treated patients who lacked matches were excluded from the study. Cox regression analysis of treated patients vs matched controls showed a significantly lower risk of mortality $(\mathrm{HR}=0.62,95 \% \mathrm{Cl}=0.57-0.68)$; lower risk of hospitalization $(\mathrm{HR}=0.71,95 \% \mathrm{Cl}=0.67-0.76$; $\mathrm{HR}=0.70,95 \% \mathrm{Cl}=0.64-0.76$ ); and lower rate in number of hospitalizations per month (incident rate ratio $[\mathrm{IRR}]=0.65,95 \% \mathrm{Cl}=0.60$ 0.71 ; IRR=0.65, 95\% Cl=0.58-0.73).

CONCLUSIONS: This study suggests that treatment with antifibrotics may confer a survival benefit and protection against all-cause and respiratory-related hospitalization for IPF patients. 
Idiopathic pulmonary fibrosis (IPF) is a chronic, progressive fibrotic interstitial lung disease (ILD) that is characterized by the absence of an identifiable cause and a specific radiologic or pathologic pattern of usual interstitial pneumonia. ${ }^{1}$ The median historic survival for patients diagnosed with IPF is 3 to 4 years, ${ }^{2-4}$ with varying clinical progression and with unpredictable periods of acute respiratory deterioration. ${ }^{5}$ Past treatment modalities were mainly supportive and failed to slow disease progression or improve quality of life. $^{6-8}$ Two novel antifibrotic drugs, pirfenidone and nintedanib, became the first treatments approved by the US Food and Drug Administration (FDA) for IPF in 2014; both were shown to slow forced vital capacity decline in randomized clinical trials..$^{9,10}$

Despite the acceptance of antifibrotic drug therapy into IPF treatment guidelines and routine clinical practice, limited data are available on the effect of antifibrotic therapy on IPF outcomes outside of clinical trials, ${ }^{2,8,11-13}$ particularly among older adults who have higher prevalence of IPF. ${ }^{3}$ The prevalence of IPF in the United States, which has a median age of onset of 60-70 years, ${ }^{6}$ has been estimated at 14.0 cases per 100,000 persons, with 38.5 and 19.5 cases per 100,000 males and females, respectively, aged older than 74 years..$^{14}$ A recent study using insurance claims for commercially insured and Medicare Advantage beneficiaries in a large US health plan found a decreased risk of all-cause mortality and acute hospitalizations in antifibrotic-treated vs untreated IPF patients..$^{15}$ Additional real-world studies are needed to more fully elucidate the effect of antifibrotic treatment in other populations.

The purpose of this study was to address the dearth of evidence on the real-world effectiveness of 2 available antifibrotic treatments. Using real-world data from Medicare beneficiaries in traditional fee-for-service (FFS) plans, we compared survival and hospitalization between beneficiaries with IPF receiving antifibrotic treatment and those not receiving antifibrotic treatment. Some of the results of this study have been previously reported in the form of abstracts. ${ }^{16,17}$

\section{Methods}

\section{STUDY DESIGN AND DATA SOURCE}

In this retrospective analysis, we examined the effectiveness of antifibrotic treatment among Medicare beneficiaries with IPF using 2010-2017 administrative claims data from the 100\% sample of Medicare beneficiaries (Research Identifiable Files). Medicare is a US health insurance program for people aged 65 years or older, younger than 65 years with certain disabilities, and of all ages with end-stage renal disease. ${ }^{18}$ We compared treated Medicare beneficiaries after antifibrotics became available with a matched cohort of untreated historical controls. This study was granted an exemption from review by the Western Institutional Review Board.

\section{PATIENT POPULATION}

We identified all Medicare beneficiaries who were diagnosed with IPF, defined as having at least 1 inpatient or at least 2 outpatient claims with an International Classification of Diseases, Ninth/Tenth Revision, Clinical Modification diagnosis code for IPF (ICD-9-CM: 516.3, 516.30, 516.31; ICD10-CM: J84.111, J84.112) during the study period (January 1, 2010-December 31, 2017). Subsequently, the following 2 groups of IPF patients were created relative to the FDA approval date for antifibrotic therapy (October 15, 2014): (1) beneficiaries who initiated antifibrotic treatment $(\geq 1$ prescription fill of pirfenidone or nintedanib) between October 15, 2014, and December 31, 2017 (ie, treated patients) and (2) beneficiaries not receiving antifibrotic treatment during a historical identification (ID) period of January 1, 2012-October 14, 2014 (ie, untreated historical controls), before the availability of antifibrotic therapy.

The 2 groups were not mutually exclusive, since patients in the untreated control group were allowed in the treatment group if they initiated treatment after October 14, 2014. Patients in the untreated control group were allowed to initiate antifibrotic use after the regulatory approval date; this was done to avoid introducing selection bias because patients with IPF who were not prescribed antifibrotic therapy once approved may have been very different than patients who initiated such therapy.

For treated patients, the first fill date in the ID period was defined as the index date; patients could not have any claims for pirfenidone or nintedanib before the index date and must have had at least 1 diagnosis of IPF before the index date. For untreated controls, at least 1 IPF diagnosis had to occur during the historical ID period, with the first IPF claim defined as the index date.

Patients in the treated and untreated groups met the following criteria: aged at least 67 years on the index date; continuously enrolled in FFS Medicare Part A, Part B, and Part D for 2 years before the index date (baseline period); and at least 1 computerized tomography (CT) scan during the baseline period, with an IPF diagnosis after a CT scan.

We excluded all patients who had a claim for another ILD diagnosis after the last observed IPF claim (to avoid potential misclassification) or received a lung transplant before their index date. 


\section{CENSORING AND FOLLOW-UP TIME}

Censoring occurred for several reasons. Patients who received a lung transplant after their index date were censored at the time of transplant. In addition, treated patients who switched or discontinued index treatment were censored at the time of switching or 60 days after their last treatment if they discontinued therapy (discontinuation was defined as a gap in use of $>60$ days). All patients were censored because of disenrollment, death, and on the study end date, which was December 31, 2017, for treated patients and October 14, 2014, the day before antifibrotic approval, for untreated patients.

Patients were not required to have a minimum follow-up time after their index date. Thus, each patient was observed from 2 years before the index date until the first occurring censoring event.

\section{PROPENSITY SCORE MATCHING AND STUDY MEASURES}

To optimize the balance of characteristics between the study groups, untreated patients were matched 1:1 to treated patients using the propensity score (nearest neighbor with caliper width of 0.2 of the SD of the logit of the propensity score). The propensity for initiating antifibrotic treatment was estimated using logistic regression containing several baseline variables: age; sex; geographic region; quartile of median income of patient residential area; distance from patient residential area to an ILD specialty center (miles); Charlson Comorbidity Index (CCI) score (modified to exclude chronic pulmonary disease); chronic obstructive pulmonary disease; selected cardiovascular conditions (atrial fibrillation, congestive heart failure, ischemic heart disease, pulmonary hypertension, stroke, and venous thromboembolism); and several proxies for disease severity.

The disease severity proxies included the following: the occurrence of pneumonia, a chest CT scan, a respiratoryrelated hospitalization and oral steroid use within 3 months before the index date; the use of oxygen and the number of respiratory-related office visits within the year before the index date; and a new diagnosis of IPF, defined as at least 1 year disease-free before the first IPF diagnosis during the baseline period. The model retained all main effects in addition to significant two-way interactions. Treated patients without a match were excluded.

All study measures were calculated using Medicare claims and the applicable ICD-9/10-CM diagnosis or procedure codes, Current Procedural Terminology codes, and prescription drug codes. The primary study outcome was death from any cause during the follow-up period. The secondary study outcomes were all-cause and respiratory-related inpatient hospitalization during follow-up; respiratory-related hospitalization was defined as an inpatient claim with a primary diagnosis of respiratory disease (ICD-9-CM: 460.xx-519.xx; ICD-10-CM: J00.xx-J99.xx).

In addition to the variables used in matching, we examined the following baseline measures: race, number of chronic conditions, ${ }^{19}$ obstructive sleep apnea, lung cancer, pneumothorax, gastroesophageal reflux, obesity, cor pulmonale, pulmonary rehabilitation and respiratory diagnostic services (in the year before index), and smoking cessation history (see Supplementary Table 1 for codes, available in online article).

\section{STATISTICAL ANALYSIS}

Descriptive statistics were generated for all baseline demographic and clinical characteristics and outcomes. Means and SDs were reported for continuous variables, and frequencies and percentages for categorical data. The risk of mortality and risk of hospitalization (all-cause and respiratory-related) were compared between treated and untreated patients using cumulative probability curves and Cox proportional hazards regression. The proportional hazard assumption was checked for all covariates; for any assumptions that did not hold, time-dependent variables (interaction term of covariate with log of time) were included. The rate of hospitalizations per month was compared using negative binomial regression.

The final Cox models and negative binomial models included all variables used in matching, in addition to the following variables, irrespective of statistical significance, to adjust for potential residual confounding: obstructive sleep apnea, lung cancer, pneumothorax, gastroesophageal reflux, obesity, pulmonary rehabilitation, and respiratory diagnostic services in the year before the index date.

All statistical tests were carried out at a significance level of 0.05. All data transformations and statistical analyses were performed using SAS version 9.4 (SAS Institute).

\section{Results}

\section{BASELINE CHARACTERISTICS}

We identified 4,993 Medicare beneficiaries diagnosed with IPF who initiated treatment with an antifibrotic medication during the ID period of October 15, 2014-December 31, 2017, and 14,316 untreated controls with a diagnosis code for IPF in the ID period of January 1, 2012-October 14, 2014, all of whom met the study criteria. After propensity score matching, 352 (7.0\%) treated patients without matches were excluded from the analysis. The final study sample included 4,641 treated patients (2,405 pirfenidone and 2,236 nintedanib) and 4,641 matched untreated controls. 


\section{TABLE 1 Baseline Demographics and Clinical Characteristics Among Medicare Beneficiaries with Idiopathic} Pulmonary Fibrosis

\begin{tabular}{|c|c|c|c|c|c|}
\hline \multirow{3}{*}{$\begin{array}{l}\text { Subjects, } n \\
\text { Age, year, mean (SD) }\end{array}$} & \multicolumn{2}{|c|}{ Treated } & \multicolumn{2}{|c|}{ Matched untreated } & \multirow{3}{*}{$\begin{array}{r}\text { P value } \\
0.642 \\
\end{array}$} \\
\hline & \multicolumn{2}{|c|}{4,641} & \multicolumn{2}{|c|}{4,641} & \\
\hline & 76.0 & $(5.6)$ & 76.1 & $(5.8)$ & \\
\hline \multicolumn{6}{|l|}{ Age category, n (\%) } \\
\hline $67-74$ & 2,025 & $(43.6)$ & 2,086 & $(44.9)$ & \multirow{3}{*}{0.151} \\
\hline $75-84$ & 2,202 & $(47.4)$ & 2,188 & $(47.1)$ & \\
\hline $85+$ & 414 & $(8.9)$ & 367 & (7.9) & \\
\hline \multicolumn{6}{|l|}{ Sex, n (\%) } \\
\hline Female & 1,735 & $(37.4)$ & 1,674 & $(36.1)$ & \multirow{2}{*}{0.189} \\
\hline Male & 2,906 & $(62.6)$ & 2,967 & $(63.9)$ & \\
\hline White, n (\%) & 4,394 & $(94.7)$ & 4,411 & $(95.0)$ & 0.424 \\
\hline \multicolumn{6}{|l|}{ Region, n (\%) } \\
\hline Midwest & 1,198 & $(25.8)$ & 1,196 & $(25.8)$ & \multirow{4}{*}{0.998} \\
\hline Northeast & 790 & $(17.0)$ & 784 & $(16.9)$ & \\
\hline South & 1,927 & $(41.5)$ & 1,934 & $(41.7)$ & \\
\hline West & 726 & $(15.6)$ & 727 & $(15.7)$ & \\
\hline \multicolumn{6}{|l|}{ Quartile of median income of residential area, ${ }^{a} \mathbf{n}(\%)$} \\
\hline Quartile 1 & 907 & $(19.5)$ & 885 & $(19.1)$ & \multirow{5}{*}{0.957} \\
\hline Quartile 2 & 1,051 & $(22.6)$ & 1,072 & $(23.1)$ & \\
\hline Quartile 3 & 1,165 & $(25.1)$ & 1,180 & $(25.4)$ & \\
\hline Quartile 4 & 1,448 & $(31.2)$ & 1,436 & $(30.9)$ & \\
\hline Unknown & 70 & $(1.5)$ & 68 & $(1.5)$ & \\
\hline Distance from residential area to ILD specialty center (miles), mean (SD) & 100 & 161.51) & 101 & (72.02) & 0.824 \\
\hline Modified CCI score, ${ }^{\mathrm{b}}$ mean (SD) & 3.3 & $(2.9)$ & 3.2 & $(2.8)$ & 0.103 \\
\hline No. of chronic conditions, mean (SD) & 7.8 & $(2.0)$ & 7.7 & $(2.0)$ & $<0.001$ \\
\hline COPD, including emphysema, n (\%) & 2,768 & $(59.6)$ & 2,816 & $(60.7)$ & 0.309 \\
\hline Obstructive sleep apnea, n (\%) & 1,585 & $(34.2)$ & 988 & $(21.3)$ & $<0.001$ \\
\hline Lung cancer, n (\%) & 119 & $(2.6)$ & 232 & $(5.0)$ & $<0.001$ \\
\hline Pneumothorax, n (\%) & 326 & $(7.0)$ & 135 & $(2.9)$ & $<0.001$ \\
\hline Gastroesophageal reflux, n (\%) & 2,724 & $(58.7)$ & 2,397 & $(51.6)$ & $<0.001$ \\
\hline Obesity, n (\%) & 1,174 & $(25.3)$ & 733 & $(15.8)$ & $<0.001$ \\
\hline \multicolumn{6}{|l|}{ Cardiovascular conditions, n (\%) } \\
\hline Atrial fibrillation & 1,043 & $(22.5)$ & 1,013 & $(21.8)$ & 0.453 \\
\hline Congestive heart failure & 1,404 & $(30.3)$ & 1,408 & $(30.3)$ & 0.928 \\
\hline Cor pulmonale & 200 & $(4.3)$ & 234 & $(5.0)$ & 0.095 \\
\hline Ischemic heart disease & 2,669 & $(57.5)$ & 2,687 & $(57.9)$ & 0.705 \\
\hline Pulmonary hypertension & 483 & $(10.4)$ & 514 & $(11.1)$ & 0.299 \\
\hline Stroke & 288 & $(6.2)$ & 266 & $(5.7)$ & 0.335 \\
\hline Venous thromboembolism & 386 & $(8.3)$ & 353 & $(7.6)$ & 0.206 \\
\hline
\end{tabular}




\section{TABLE 1 Baseline Demographics and Clinical Characteristics Among Medicare Beneficiaries with Idiopathic Pulmonary Fibrosis (continued)}

\begin{tabular}{|c|c|c|c|c|c|}
\hline \multirow[b]{2}{*}{ Smoking cessation therapy, n (\%) } & \multicolumn{2}{|c|}{ Treated } & \multicolumn{2}{|c|}{ Matched untreated } & \multirow{2}{*}{$\begin{array}{c}\text { P value } \\
0.019\end{array}$} \\
\hline & 186 & $(4.0)$ & 144 & $(3.1)$ & \\
\hline Respiratory hospitalization within 3 months before index, n (\%) & 567 & $(12.2)$ & 549 & $(11.8)$ & 0.566 \\
\hline Receiving a CT scan within 3 months before index, n (\%) & 2,195 & $(47.3)$ & 2,123 & $(45.7)$ & 0.134 \\
\hline Pneumonia (bacterial or viral) within 3 months before index, $\mathrm{n}(\%)$ & 577 & $(12.4)$ & 545 & $(11.7)$ & 0.308 \\
\hline Receiving oral corticosteroids within 3 months before index, n (\%) & 1,584 & $(34.1)$ & 1,664 & $(35.9)$ & 0.082 \\
\hline Oxygen use within 1 year before index, ${ }^{c} \mathrm{n}(\%)$ & 2,739 & $(59.0)$ & 2,810 & $(60.5)$ & 0.133 \\
\hline Respiratory-related office visits within 1 year before index, mean (SD) & 7.32 & $(5.54)$ & 7.11 & $(7.03)$ & 0.119 \\
\hline Pulmonary rehabilitation within 1 year before index, n (\%) & 651 & $(14.0)$ & 381 & $(8.2)$ & $<0.001$ \\
\hline Respiratory diagnostic services within 1 year before index, n (\%) & 4,450 & $(95.9)$ & 3,800 & $(81.9)$ & $<0.001$ \\
\hline Newly diagnosed IPF patients, n (\%) & 2,989 & $(64.4)$ & 2,961 & $(63.8)$ & 0.545 \\
\hline
\end{tabular}

ancome quartiles based on an external population derived from Healthcare Cost and Utilization Project (HCUP) Nationwide Inpatient Sample.

${ }^{b}$ Excludes chronic pulmonary disease.

cNumbers of patients with evidence of an oxygen flow rate of $\geq 4$ liters/minute were 5 and 4 for pirfenidone and nintedanib users, respectively.

$\mathrm{CCl}=$ Charlson Comorbidity Index; $\mathrm{COPD}=$ chronic obstructive pulmonary disease; $C T=$ computerized tomography; ILD =interstitial lung disease; IPF $=$ idiopathic pulmonary fibrosis.

\section{TABLE 2 Deaths and Hospitalizations in Follow-Up Period Among} Medicare Beneficiaries with Idiopathic Pulmonary Fibrosis

\begin{tabular}{|c|c|c|c|}
\hline & Treated & Matched untreated & $P$ value \\
\hline Subjects, $\mathrm{n}$ & 4,641 & 4,641 & \\
\hline Days of follow-up, ${ }^{a}$ mean (SD) & $332.3(281.1)$ & $474.0(329.3)$ & \\
\hline Death, n (\%) & $826(17.8)$ & $1,777 \quad(38.3)$ & $<0.001^{c}$ \\
\hline \multicolumn{4}{|c|}{ Hospitalizations per patient month, mean (SD) } \\
\hline All-cause hospitalization & $0.104 \quad(0.33)$ & $0.160 \quad(0.41)$ & $<0.001^{\mathrm{d}}$ \\
\hline Respiratory-related hospitalization ${ }^{\mathrm{b}}$ & $0.052(0.24)$ & $0.085(0.31)$ & $<0.001^{\mathrm{d}}$ \\
\hline
\end{tabular}

apatients were observed from 2 years before the index date until the first occurring censoring event. 'Inpatient claims with primary diagnosis of respiratory disease (ICD-9-CM: 460.xx-519.xx; ICD-10-CM: J00.xx-J99.xx) or outpatient claims with any diagnosis of respiratory disease.

'Chi-square test.

${ }^{d}$ Wald chi-square test based on negative binomial model.

ICD-9/10-CM = International Classification of Diseases, Ninth/Tenth Revision, Clinical Modification.

The baseline demographic characteristics were similar between the study groups (Table 1). Mean (SD) age at index was 76.0 (5.6) years for treated patients and 76.1 (5.8) years for untreated controls $(P=0.642)$. Beneficiaries in both groups were mostly male (62.6\% vs $63.9 \%, \mathrm{P}=0.189)$ and White (94.7\% vs $95.0 \%, P=0.424)$ and represented all geographic regions and residential income quartiles. The mean (SD) modified CCI was 3.3 (2.9) and 3.2 (2.8; $P=0.103)$, which reflected considerable morbidity in both groups, as do the frequencies of atrial fibrillation $(22.5 \%$ vs $21.8 \%$,
$\mathrm{P}=0.453)$, congestive heart failure (30.3\% vs $30.3 \%, P=0.928)$, and ischemic heart disease $(57.5 \%$ vs $57.9 \%$, $\mathrm{P}=0.705$ ).

Notably, several observed characteristics not included in the matching process were differentbetween treated and matched untreated controls, such as obstructive sleep apnea $(34.2 \%$ vs $21.3 \%, P<0.001)$, lung cancer $(2.6 \%$ vs $5.0 \%, \mathrm{P}<0.001)$, pneumothorax $(7.0 \%$ vs $2.9 \%, \mathrm{P}<0.001)$, gastroesophageal reflux $(58.7 \%$ vs $51.6 \%, \quad \mathrm{P}<0.001)$, obesity $(25.3 \%$ vs $15.8 \%, P<0.001)$, pulmonary rehabilitation $(14.0 \%$ vs $8.2 \%, \mathrm{P}<0.001)$, respiratory diagnostic services $(95.9 \%$ vs $81.9 \%, \mathrm{P}<0.001)$, and smoking cessation therapy $(4.0 \%$ vs $3.1 \%, \mathrm{P}=0.019$; Table 1 ).

Examining proxies for disease severity, assessed during the 3 months before the index date, $12.2 \%$ of treated patients vs $11.8 \%(P=0.566)$ of untreated controls had a respiratory hospitalization; $47.3 \%$ and $45.7 \%$ $(P=0.134)$ received a CT scan; $12.4 \%$ vs $11.7 \%(\mathrm{P}=0.308)$ had pneumonia; and $34.1 \%$ vs $35.9 \%(P=0.082)$ received an 


\section{FIGURE 1 Risk of Mortality ${ }^{a}$}

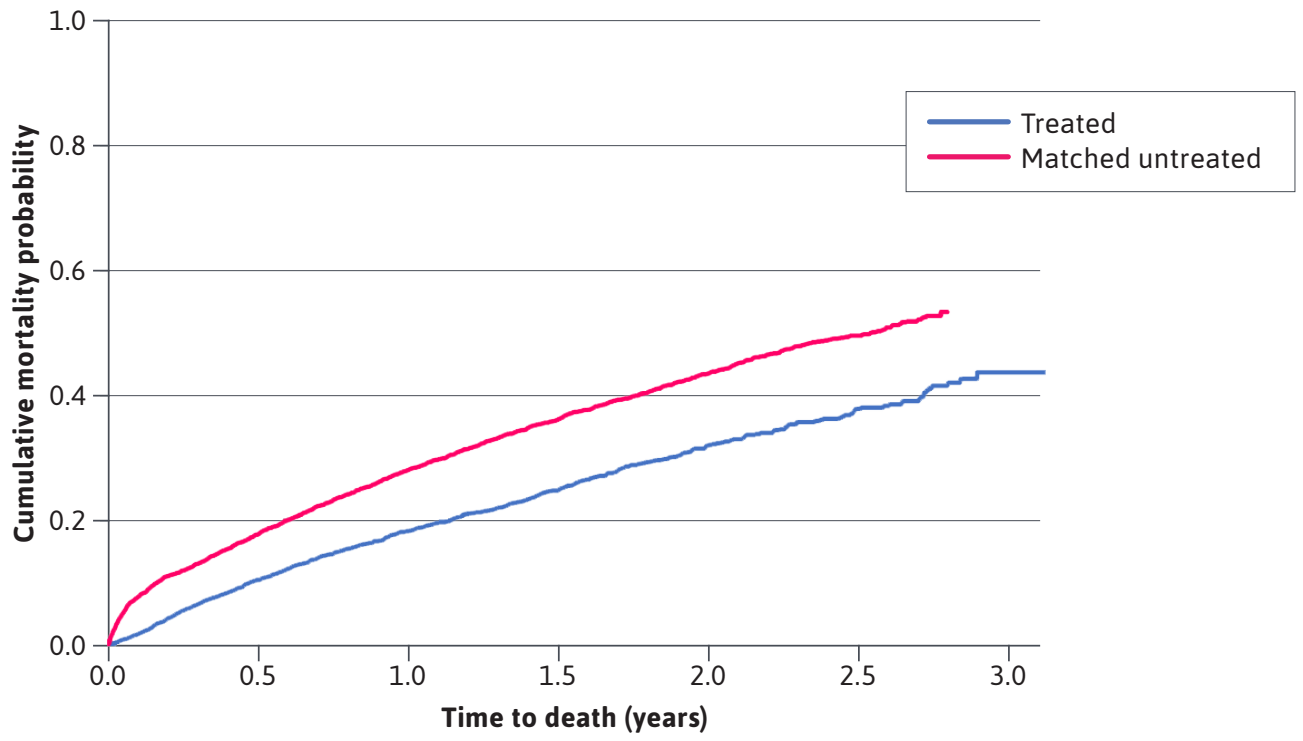

\begin{tabular}{|c|c|c|c|c|c|c|c|c|}
\hline & \multicolumn{2}{|c|}{ At 6 months } & \multicolumn{2}{|c|}{ At 1 year } & \multicolumn{2}{|c|}{ At 2 years } & \multicolumn{2}{|c|}{ At 2.5 years } \\
\hline & $\begin{array}{c}\text { Cumulative } \\
\text { mortality } \\
\text { probability } \\
(95 \% \mathrm{CI})\end{array}$ & At risk & $\begin{array}{c}\text { Cumulative } \\
\text { mortality } \\
\text { probability } \\
(95 \% \mathrm{CI})\end{array}$ & At risk & $\begin{array}{c}\text { Cumulative } \\
\text { mortality } \\
\text { probability } \\
(95 \% \mathrm{CI})\end{array}$ & At risk & $\begin{array}{c}\text { Cumulative } \\
\text { mortality } \\
\text { probability } \\
(95 \% \mathrm{CI})\end{array}$ & At risk \\
\hline Treated & $\begin{array}{c}0.102 \\
(0.093-0.112)\end{array}$ & 2,652 & $\begin{array}{c}0.180 \\
(0.166-0.194)\end{array}$ & 1,578 & $\begin{array}{c}0.315 \\
(0.293-0.338)\end{array}$ & 564 & $\begin{array}{c}0.374 \\
(0.347-0.402)\end{array}$ & 311 \\
\hline Matched untreated & $\begin{array}{c}0.174 \\
(0.163-0.186)\end{array}$ & 3,434 & $\begin{array}{c}0.276 \\
(0.263-0.290)\end{array}$ & 2,607 & $\begin{array}{c}0.428 \\
(0.412-0.445)\end{array}$ & 1,311 & $\begin{array}{c}0.486 \\
(0.468-0.505)\end{array}$ & 684 \\
\hline
\end{tabular}

Note: The adjusted hazard ratio generated from the Cox proportional hazards regression analysis was $0.62(95 \% \mathrm{Cl}=0.57-0.68)$.

aThe cumulative probability curve for mortality revealed a lower risk of mortality over time for treated patients compared with untreated controls.

oral corticosteroid. In the year before the index date, $14.0 \%$ of treated patients received pulmonary rehabilitation compared with $8.2 \%(P<0.001)$ of controls. Nearly two-thirds of patients in each group were newly diagnosed $(64.4 \%$ vs $63.8 \%, P=0.545$; Table 1).

\section{RISK OF MORTALITY}

After adjusting for differences between the groups, patients treated with antifibrotic therapy had a mean (SD) follow-up length of 332.3 (281.1) days vs 474.0 (329.3) days for untreated controls (Table 2). Over the course of follow-up, 826 (17.8\%) treated patients died compared with 1,777 (38.3\%) controls $(\mathrm{P}<0.001)$. The cumulative probability curve for mortality revealed a lower risk of mortality over time for treated patients compared with untreated controls (log-rank $\mathrm{P}<0.001$; Figure 1). Similarly, the Cox proportional hazards model demonstrated a significant difference in mortality risk between the treated patients vs untreated controls (hazard ratio $[\mathrm{HR}]=0.62,95 \% \mathrm{CI}=0.57-0.68$ ), adjusting for covariates (Table 3).

\section{RISK AND RATE OF HOSPITALIZATION}

Compared with untreated controls, treated patients had fewer all-cause and respiratory-related hospitalizations per month $(0.104$ [0.33] vs 0.160 [0.41], $\mathrm{P}<0.001$ and 0.052 [0.24] vs 0.085 [0.31], $P<0.001$, for treated and untreated respectively; Table 2). The probability of having a hospitalization for any cause was lower for treated patients at all points in time; this was also true for respiratory-related hospitalization (log-rank $\mathrm{P}<0.001$, both; Figure 2 and Supplementary Figure 1, available in online article). The estimated HRs (95\% CI) from the Cox regression showed a corresponding lower risk of all-cause and respiratory-related hospitalization for treated patients vs untreated controls $(\mathrm{HR}=0.71$, 


\section{TABLE 3 Risk of Mortality and Risk and Rate of Hospitalization Among Medicare Beneficiaries with Idiopathic Pulmonary Fibrosis, Treated vs Not Treated with Antifibrotics}

\begin{tabular}{|c|c|c|c|c|c|}
\hline \multirow[b]{3}{*}{ Parameter ${ }^{a}$} & \multirow[b]{2}{*}{ Risk of mortality } & \multicolumn{2}{|c|}{ Risk of hospitalization } & \multicolumn{2}{|c|}{ Rate of hospitalizations per month } \\
\hline & & $\begin{array}{c}\text { All-cause } \\
\text { hospitalization }\end{array}$ & $\begin{array}{l}\text { Respiratory-related } \\
\text { hospitalization }\end{array}$ & $\begin{array}{c}\text { All-cause } \\
\text { hospitalization }\end{array}$ & $\begin{array}{l}\text { Respiratory-related } \\
\text { hospitalization }\end{array}$ \\
\hline & $\mathrm{HR}(95 \% \mathrm{CI})$ & HR $(95 \% \mathrm{CI})$ & $\mathrm{HR}(95 \% \mathrm{Cl})$ & IRR (95\% CI) & IRR (95\% CI) \\
\hline $\begin{array}{l}\text { Treated }(n=4,641) \text { vs } \\
\text { matched untreated }(n=4,641)\end{array}$ & $0.62(0.57-0.68)$ & $0.71(0.67-0.76)$ & $0.70(0.64-0.76)$ & $0.65(0.60-0.71)$ & $0.65(0.58-0.73)$ \\
\hline
\end{tabular}

${ }^{a}$ All models were adjusted for the following baseline covariates: age, sex, geographic region, quartile of median income of patient residential area, distance from patient residential area to an ILD specialty center (miles), CCI score (modified to exclude chronic pulmonary disease), COPD, atrial fibrillation, congestive heart failure, ischemic heart disease, pulmonary hypertension, stroke, and venous thromboembolism; pneumonia, CT scan, respiratory-related hospitalization, or oral steroid use within 3 months before index; oxygen use and number of respiratory-related office visits in the year before index; newly diagnosed IPF; and obstructive sleep apnea, lung cancer, pneumothorax, gastroesophageal reflux, obesity, and pulmonary rehabilitation and respiratory diagnostic services in the year before index. The model retained all main effects in addition to significant 2-way interactions.

$\mathrm{CCl}=$ Charlson Comorbidity Index; $\mathrm{COPD}=$ chronic obstructive pulmonary disease; $C T=$ computerized tomography; $H R=$ hazard ratio; ILD=interstitial lung disease; $I P F=$ idiopathic pulmonary fibrosis; IRR=incidence rate ratio.

95\% CI $=0.67-0.76$ and $\mathrm{HR}=0.70,95 \% \mathrm{CI}=0.64-0.76$, respectively; Table 3 and Figure 1). In addition, treated patients had a significantly lower rate of all-cause and respiratoryrelated hospitalizations per patient month compared with untreated controls (incidence rate ratio $[\mathrm{IRR}]=0.65,95 \%$ $\mathrm{CI}=0.60-0.71$ and $\mathrm{IRR}=0.65,95 \% \mathrm{CI}=0.58-0.73)$, respectively; Table 3).

\section{Discussion}

This observational study of Medicare beneficiaries provides new evidence of the effectiveness of antifibrotic therapy in treating IPF. We compared outcomes for beneficiaries diagnosed with IPF who initiated treatment with pirfenidone or nintedanib with an untreated historical cohort of beneficiaries and found that use of an antifibrotic medication was associated with a $38 \%$ reduction in the risk of dying. In addition, treated patients had a lower risk of all-cause hospitalization (29\% reduction) and respiratory-related hospitalization (30\% reduction) and experienced 35\% fewer hospitalizations per month than untreated patients.

We believe that the findings from this real-world study have salience for 2 reasons. First, evidence that antifibrotic therapy confers survival benefits underscores the importance of timely initiation of this treatment in patients with IPF. Despite the acceptance of antifibrotic drug therapy into IPF treatment guidelines, research has shown that many patients remain untreated..$^{2,20,21}$ Maher et al found that in 2016 54\% of patients with IPF from 5 countries in Europe did not receive antifibrotic treatment. ${ }^{20}$ Potential factors behind this finding include a lack of awareness of available antifibrotic therapies and their effectiveness, delayed diagnosis of IPF and subsequent treatment, and adoption of a "watch and wait" approach by physicians..$^{2,20,21}$ In addition, patients with less severe disease are less likely to receive antifibrotic treatment compared with those with severe IPF. ${ }^{2,20,21}$ Second, the study revealed real-world evidence of the effectiveness of antifibrotic treatment among patients with advanced age (ie, aged older than 80 years), which is a population that has been excluded from key clinical trials despite being disproportionately affected by IPF. 10,22

Put into broader context, the results of this study are consistent with and extend the existing literature regarding antifibrotic effectiveness in the real world. A recent study that examined patients with IPF enrolled in commercial and Medicare Advantage health plans from 2014-2018 found a comparable reduction in risk of all-cause mortality (23\%) and acute hospitalization (30\%) among antifibrotic-treated vs untreated IPF patients. ${ }^{15}$ Patients in this study were younger than in the present analysis (72 years vs 76 years) and represented a different insurance population, which may account for the small difference in the treatment effect estimates. In addition, the former study selected a contemporaneous comparison group of untreated patients, which may also explain differences in our estimates, as such patients were likely different than treated patients in unobserved ways because of their treatment status in a period of antifibrotic availability.

Our analysis also adds to this initial study by providing evidence of a beneficial treatment effect on respiratoryrelated hospitalization. Combined with our findings on mortality, our study lends support to previous research that has suggested a strong correlation between respiratory hospitalization and death. ${ }^{23}$ 


\section{FIGURE 2 Risk of All-Cause Hospitalization ${ }^{2}$}

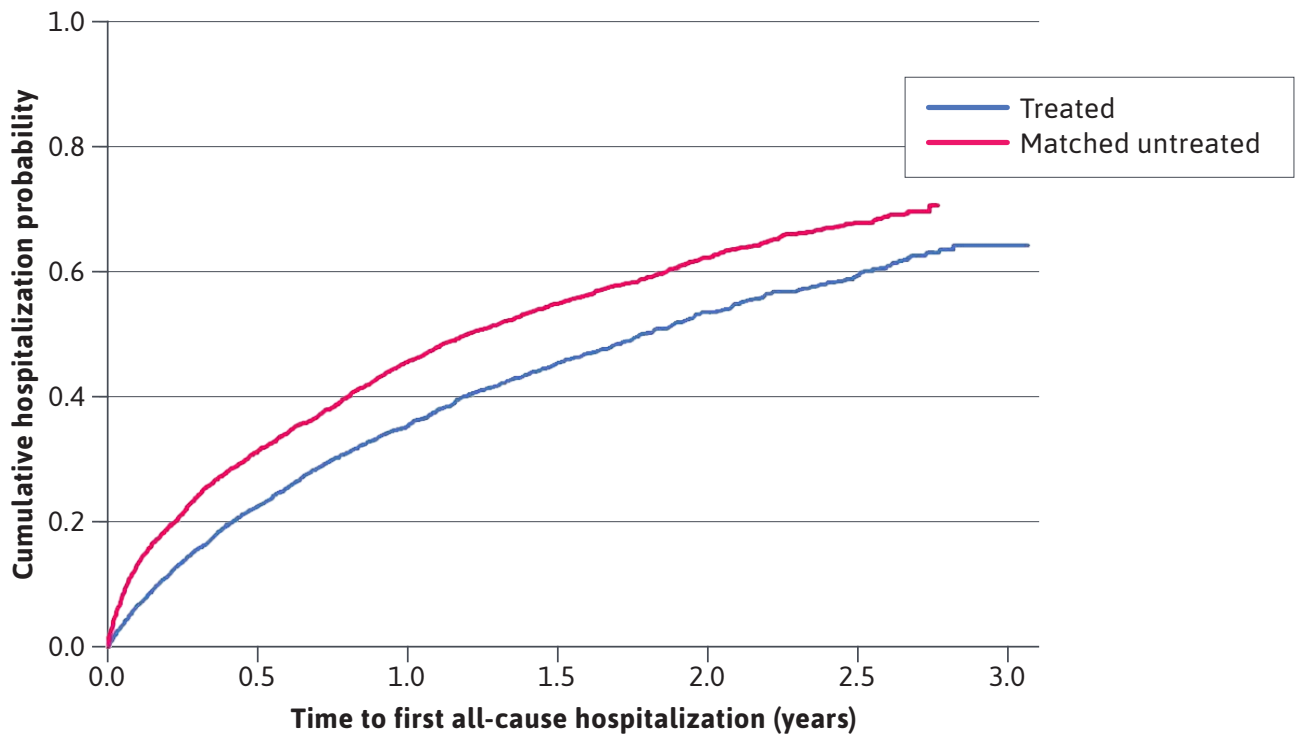

\begin{tabular}{|c|c|c|c|c|c|c|c|c|}
\hline & \multicolumn{2}{|c|}{ At 6 months } & \multicolumn{2}{|c|}{ At 1 year } & \multicolumn{2}{|c|}{ At 2 years } & \multicolumn{2}{|c|}{ At 2.5 years } \\
\hline & $\begin{array}{c}\text { Cumulative } \\
\text { mortality } \\
\text { probability } \\
(95 \% \mathrm{CI})\end{array}$ & At risk & $\begin{array}{c}\text { Cumulative } \\
\text { mortality } \\
\text { probability } \\
(95 \% \mathrm{CI})\end{array}$ & At risk & $\begin{array}{c}\text { Cumulative } \\
\text { mortality } \\
\text { probability } \\
(95 \% \mathrm{CI})\end{array}$ & At risk & $\begin{array}{c}\text { Cumulative } \\
\text { mortality } \\
\text { probability } \\
(95 \% \mathrm{CI})\end{array}$ & At risk \\
\hline Treated & $\begin{array}{c}0.225 \\
(0.212-0.238)\end{array}$ & 2,277 & $\begin{array}{c}0.352 \\
(0.336-0.370) \\
\end{array}$ & 1,246 & $\begin{array}{c}0.535 \\
(0.511-0.559) \\
\end{array}$ & 374 & $\begin{array}{c}0.590 \\
(0.563-0.618)\end{array}$ & 195 \\
\hline Matched untreated & $\begin{array}{c}0.312 \\
(0.298-0.326)\end{array}$ & 2,625 & $\begin{array}{c}0.455 \\
(0.439-0.471)\end{array}$ & 1,731 & $\begin{array}{c}0.622 \\
(0.604-0.639)\end{array}$ & 718 & $\begin{array}{c}0.676 \\
(0.658-0.695)\end{array}$ & 195 \\
\hline
\end{tabular}

Note: The adjusted hazard ratio generated from the Cox proportional hazards regression analysis was $0.71(95 \% \mathrm{Cl}=0.67-0.76)$.

aThe probability of having an all-cause hospitalization was lower for treated vs untreated patients at all points in time.

\section{LIMITATIONS}

Our study has several limitations to consider. First, we were unable to confirm an IPF diagnosis, so it is possible, especially for the untreated cohort, that patients with other ILDs may have been included in the analysis.

Second, some beneficiaries may have participated in clinical trials before the approval of antifibrotics. As a result, some patients classified as newly treated at index or classified as untreated in the historical period may have been incorrectly classified, since trial treatments do not generally appear in Medicare claims. We believe such misclassification was uncommon and would have biased the results toward a null outcome.

Third, our study design allowed untreated controls to also be in the treated group if they initiated treatment after October 14, 2014. This was done to avoid bias from selecting only historical controls who were not eventually put on antifibrotic therapy and who would likely be different than treated patients. However, only $3 \%$ of patients $(n=291)$ were included in both groups, and no patient served as their own matched control, suggesting this had a minimal impact.

Fourth, despite use of robust matching procedures to balance observed characteristics across study groups, we were unable to fully control for unobserved differences. These characteristics could have included differences in disease severity between the cohorts, which may have affected outcomes beyond treatment effects. Although we analyzed several proxies for disease severity, it was not possible to fully adjust for disease severity.

Fifth, our study findings are limited to FFS Medicare beneficiaries who were aged at least 67 years so cannot be generalized to other, including younger, populations.

Finally, the effect of antifibrotic therapy on quality of life, including adverse effects of medicines or other 
determinants of health, was not examined in this analysis but may give rise to future investigation of the broader health effects of antifibrotic treatment.

\section{Conclusions}

The use of antifibrotics is associated with significant health and survival benefits to Medicare beneficiaries who are diagnosed with IPF. Antifibrotic therapy appears to show a significant protective effect, reducing mortality and all-cause and respiratory-related hospitalizations and should be considered as part of a disease management plan for a broad array of IPF patients, including those of advanced age.

\section{DISCLOSURES}

This work was sponsored by F. Hoffmann-La Roche/Genentech, Inc. Corral is employed by Genentech, Inc. Reddy, Chang, Broder, and Gokhale are employed by Partnership for Health Analytic Research LLC, a health services research company, which was hired by Genentech to conduct this research.

Mooney has received advisory board/ consulting fees and research support from Genentech, unrelated to this work. Mooney also reports advisory board/consulting fees and research support from Boehringer Ingelheim; personal fees from Imvaria; and grants from Celgene and $\mathrm{Pli}^{-}$ ant, unrelated to this work.

Through their employment with Partnership for Health Analytic Research, Reddy, Chang, Broder, and Gokhale have been compensated to conduct research for AbbVie, Akcea, ASPC, Amgen, AstraZeneca, BMS, Boston Scientific Corporation, Celgene, Eisai, Ethicon, GRAIL, Helsinn, Illumina, Innovation and Value Initiative, Ionis, Jazz, Kite, Novartis, Otsuka, Pathnostics, PhRMA, Prothena, Sage, Verde Technologies, Genentech, Inc., Greenwich Biosciences, Inc., Mirum Pharmaceuticals, Inc., Sanofi US Services, Inc., Sunovion Pharmaceuticals, Inc., and Dompe US, Inc., unrelated to this work.
This research was presented as an abstract at CHEST 2020 Annual Meeting (virtual), October 18-21, 2020, and American Thoracic Society 2020 Virtual Meeting, June 2020.

\section{REFERENCES}

1. Lederer DJ, Martinez FJ. Idiopathic pulmonary fibrosis. N Engl J Med. 2018;378(19):1811-23. doi:10.1056/ NEJMra1705751

2. Maher TM, Strek ME. Antifibrotic therapy for idiopathic pulmonary fibrosis: time to treat. Respir Res. 2019;20(1):205. doi:10.1186/S12931-019-1161-4

3. Raghu G, Chen S-Y, Yeh W-S, et al. Idiopathic pulmonary fibrosis in US Medicare beneficiaries aged 65 years and older: incidence, prevalence, and survival 2001-11. Lancet Respir Med. 2014;2(7):56672. doi:10.1016/S2213-2600(14)70101-8

4. Strongman H, Kausar I, Maher TM. Incidence, prevalence, and survival of patients with idiopathic pulmonary fibrosis in the UK. Adv Ther. 2018;35(5):724-36. doi:10.1007/S12325-018-0693-1

5. Ley B, Collard HR, King TE. Clinical course and prediction of survival in idiopathic pulmonary fibrosis. Am J Respir Crit Care Med. 2011;183(4):431-40. doi:10.1164/rccm.201006-0894ci

6. Raghu G, Collard HR, Egan JJ, et al. An official ATS/ERS/JRS/ALAT statement: idiopathic pulmonary fibrosis: evidence-based guidelines for diagnosis and management. Am J Respir Crit Care Med. 2011;183(6):788-24. doi:10.1164/ rccm.2009-040gl

7. Meyer KC, Danoff SK, Lancaster LH, Nathan SD. Management of idiopathic pulmonary fibrosis in the elderly patient. Chest. 2015;148(1):242-52. doi:10.1378/ chest.14-2475

8. Tzouvelekis A, Bonella F, Spagnolo P. Update on therapeutic management of idiopathic pulmonary fibrosis. Ther Clin Risk Manag. 2015;11:359-70. doi:10.2147/ tcrm.S69716
9. Richeldi L, Du Bois RM, Raghu G, et al. Efficacy and safety of nintedanib in idiopathic pulmonary fibrosis. N Engl J Med. 2014;370(22):2071-82. doi:10.1056/ NEJMoa1402584

10. King TE, Bradford WZ, CastroBernardini S, et al. A phase 3 trial of pirfenidone in patients with idiopathic pulmonary fibrosis. N Engl J Med. 2014;370(22):2083-92. doi:10.1056/ NEJMoa1402582

11. Saito S, Alkhatib A, Kolls JK, Kondoh Y, Lasky JA. Pharmacotherapy and adjunctive treatment for idiopathic pulmonary fibrosis (IPF). J Thorac Dis. 2019;11(Suppl 14):S1740-S1754. doi:10.21037/jtd.2019.04.62

12. Raghu G, Rochwerg B, Zhang Y, et al. An official ATS/ERS/JRS/ALAT clinical practice guideline: treatment of idiopathic pulmonary fibrosis. an update of the 2011 clinical practice guideline. Am J Respir Crit Care Med. 2015;192(2):E3-E19. doi:10.1164/rccm.201506-1063st

13. Robalo-Cordeiro C, Campos $\mathrm{P}$, Carvalho L, et al. Idiopathic pulmonary fibrosis in the era of antifibrotic therapy: searching for new opportunities grounded in evidence. Rev Port Pneumol Engl Ed. 2017;23(5):287-93. doi:10.1016/j. rppnen.2017.05.005

14. Raghu G, Weycker D, Edelsberg J, Bradford WZ, Oster G. Incidence and prevalence of idiopathic pulmonary fibrosis. Am J Respir Crit Care Med. 2006;174(7):810-16. doi:10.1164/ rccm.200602-163oc

15. Dempsey TM, Sangaralingham LR, Yao X, Sanghavi D, Shah ND, Limper AH. Clinical effectiveness of antifibrotic medications for idiopathic pulmonary fibrosis. Am J Respir Crit Care Med. 2019;200(2):168-74. doi:10.1164/ rccm.201902-0456oc

16. Mooney JJ, Reddy SR, Chang E, Broder MS, Gokhale S, Corral M. Outcomes In patients with IPF treated with antifibrotic therapies compared with untreated patients in the U.S. Medicare population [abstract]. Am J Respir Crit Care Med. 2020;201:A1104. doi:10.1164/ ajrccm-conference.2020.201.1_meetingabstracts.A1104 
17. Corral M, Chang E, Broder M, Gokhale S, Reddy S. Healthcare resource use and cost in antifibrotictreated vs untreated patients with idiopathic pulmonary fibrosis (IPF) in the US Medicare population [abstract]. Chest. 2020;158(4):A1057. doi:10.1016/j. chest.2020.08.978

18. Centers for Medicare \& Medicaid Services. Medicare program - general information. Updated January 14, 2021. Accessed October 21, 2021. https:// www.cms.gov/medicare/medicaregeneral-information/medicaregeninfo/ index

19. Healthcare Cost and Utilization Project (HCUP). Chronic Condition Indicator (CCI). May 2016. Agency for Healthcare and Research Quality. Accessed October 21, 2021. https://www.hcup-us.ahrq.gov/ toolssoftware/chronic/chronic.jsp
20. Maher TM, Molina-Molina M, Russell A-M, et al. Unmet needs in the treatment of idiopathic pulmonary fibrosis-insights from patient chart review in five European countries. BMC Pulm Med. 2017;17(1):124. doi:10.1186/ S12890-017-0468-5

21. Salisbury M, Conoscenti C, Culver D, et al. Treatment patterns in patients with idiopathic pulmonary fibrosis (IPF): data from the IPF-Pro Registry [abstract]. Am J Respir Crit Care Med. 2019;199:A5622. doi: 101164/ajrccm-conference.2019.199.1_ Meetingabstracts.A5622
22. Lancaster LH, De Andrade JA, Zibrak JD, et al. Pirfenidone safety and adverse event management in idiopathic pulmonary fibrosis. Eur Respir Rev. 2017;26(146):170057. doi:10.1183/16000617.0057-2017

23. Ley B, Swigris J, Day B, et al. Pirfenidone reduces respiratory-related hospitalizations in idiopathic pulmonary fibrosis. Am J Respir Crit Care Med. 2017;196(6):756-61. doi:10.1164/ rccm.201701-0091oc 